\title{
AOR
}

Selected Papers of \#AoIR2020:

The 22nd Annual Conference of the Association of Internet Researchers Virtual Event / 13-16 Oct 2021

\section{DESIGN CHOICES: MECHANISM DESIGN AND PLATFORM CAPITALISM}

Salomé Viljoen

Columbia Law School, Columbia University

Jake Goldenfein

Melbourne Law School, University of Melbourne and ARC Centre of Excellence for Automated Decision-Making and Society

Lee McGuigan

Hussman School of Journalism and Media, University of North Carolina at Chapel Hill

Digital platforms have been built into infrastructures for organizing an increasing range of social, economic, and cultural activities. Consternation about the power of these platforms is a hallmark of the present moment. Through automated and algorithmic tools and methods, companies like Google, Facebook, Amazon, and Uber seem to exercise a special capacity for managing their customers, competitors, and workers (Darmody and Zwick, 2020; Shapiro, 2020; Yeung, 2017). They have many sources of leverage, including the monopoly power permitted under moribund antitrust enforcement (Srinivasan, 2020), regulatory blackholes that relieve them of social responsibilities (Rosenblat and Stark, 2016), and informational advantages owing to their position between buyers and sellers (Mansell and Steinmeuller, 2020). To these concerns we add a critical focus on the intellectual technologies powering these platforms - a specific set of disciplinary tools and methods deployed in their theorization, development and operation. Core operations at Google, Facebook, and beyond derive from a research discipline that treats asymmetrical accumulation of data and profiling capacity, and the optimization of actors' choices, as fundamental design principles. In this paper, we pull back the curtain of platform capitalism to glimpse the world of mechanism design.

Suggested Citation (APA): Viljoen, S. Goldenfein, J. McGuigan, L., (2021, October). Design Choices: Mechanism Design and Platform Capitalism. Paper presented at AolR 2021: The 22nd Annual Conference of the Association of Internet Researchers. Virtual Event: AolR. Retrieved from http://spir.aoir.org. 
Mechanism design brings a formidable but conflicted lineage into the heart of platform governance. With its origins in Nobel Prize-winning economic theory, mechanism design claims to be a set of methods tailored expressly to achieve social welfare by harnessing the self-interested rationality and autonomy of individuals. Mechanism design creates bespoke markets and auctions that direct individuals' choices toward outcomes that maximize a formally defined social welfare. Its ideological and normative commitments to rationality and autonomy have provided market-makers with a persuasive justification for exercising strategic control over the environments where people interact and make decisions. The apparent power of mechanism design to orchestrate forms of social coordination has earned multiple Nobel Prizes for the discipline's leading proponents (Maskin, 2008), and helped to propagate its influence beyond conventional economic settings. Mechanism design is seen to provide a set of intellectual technologies for enacting "optimization" as a worldview and a powerful idiom for a great deal of policymaking. And it has gained particular currency in areas where computers and algorithms mediate the actions of agents (Varian, 1995, 2010; Einav and Levin, 2014; Papadimitriou, 2001).

Largely without critical scrutiny, computational adaptations of mechanism design (and related management sciences, such as operations research) have become a major force in governing online environments and platforms. The experiences of almost all web and mobile app users are organized, in part, by optimizing schemes from mechanism design - such as the advertising auctions that monetize online traffic and the decision systems that configure Facebook newsfeeds. As Google's chief economist Hal Varian (2010: 4) puts it, "Online advertising serves as a poster child for algorithmic mechanism design." There is accordingly considerable scope for augmenting discussions of platform and algorithmic governance with an analysis of how the intellectual tools of mechanism design are applied in those environments.

We argue that these computational applications warrant a critical reassessment of how this discipline tries to design choices. Contrary to the legitimizing premises introduced above, the mechanism design methods and techniques underpinning digital platforms actually threaten social welfare and distort collective interests for platform firms' own ends. Platforms now use mechanism design to leverage data science and automation toward goals that dispense with the normative commitments assumed in its economic theorization. Drawing examples from online advertising auctions and the multi-sided market platforms that coordinate gig-labor and on-demand services, we illustrate how firms instrumentalize mechanism design to achieve information asymmetry, to distribute social costs in ways that benefit designers, and to orchestrate behaviors and choices in their systems.

The paper offers four contributions to the scholarship on platform governance. First, it provides a critical introduction to mechanism design (and so-called automated mechanism design) for researchers who study big data, platform capitalism, and the values designed into technologies like algorithms and artificial intelligence. So far, most critical work in these areas has not engaged directly with this hybrid economicengineering discipline, even though it is now central to the operations of platform firms, as well as other online networks and data-driven decision-making systems. A fluency in the vocabulary and techniques of mechanism design will help critical researchers 
translate and intervene in debates across these fields of science, policymaking, and industrial practice.

Second, we identify contradictions in the normative, ideological, and political commitments claimed by mechanism design's two main traditions: one descended from game theory and welfare economics, the other oriented around experimentation and applied computation. The digital uptake of mechanism design has papered over profound differences in how these two traditions define and operationalize key concepts, including the actor/subject, and its relationship to autonomous, rational decision-making.

Third, we look at how platform companies deploy and exploit mechanism design. We show how automated or algorithmic mechanism design operationalizes and progresses through the contradiction noted above, leveraging both the prestige and elegance of mechanism design's game theory tradition, as well as the brute force of the computational and statistical techniques honed by mechanism design's experimental tradition.

Finally, we provide insights into how automated mechanism design (AMD) extends the political project of installing automated market-like institutions to orchestrate social choices and allocate opportunities and value across more and more settings, while at the same time abandoning the normative commitment to autonomy and the ideological commitment to rationality that have been key to mechanism design's justification (Tomasetti, 2016). Put another way, the deployment of mechanism design in digital platforms carries forward the normative justification of markets into settings that seem like markets but operate more like control infrastructures.

Overall, our critique of mechanism design makes interventions in two directions: it gives critical researchers new insights into the discipline behind certain pathologies of platform capitalism; and it asks mechanism designers to look critically at the contradictions and pathologies within the discipline itself.

\section{References}

Darmody A and Zwick D (2020) Manipulate to empower: Hyper-relevance and the contradictions of marketing in the age of surveillance capitalism. Big Data \& Society (Jan-June): 1-12.

Shapiro A (2020) Dynamic exploits: Calculative asymmetries in the on-demand economy. New Technology, Work, and Employment 35(2): 162-177.

Yeung K (2017) 'Hypernudge': Big data as a mode of regulation by design. Information, Communication \& Society 20(1): 118-136.

Srinivasan D (2020) Why Google dominates advertising markets. Stanford Technology Law Review 24(1): 55-174. 
Rosenblat A and Stark L (2016) Algorithmic labor and information asymmetries: A case study of Uber's drivers. International Journal of Communication 10(27): 10-27.

Mansell R and Steinmueller WE (2020) Advanced Introduction to Platform Economics. Cheltenham, UK: Edward Elgar Publishing.

Maskin E (2008) Mechanism design: How to implement social goals. American Economic Review 98(3): 567-576.

Varian HR (1995) Economic mechanism design for computerized agents. Proceedings of the First USENIX Workshop on Electronic Commerce.

Varian HR (2010) Computer mediated transactions. American Economic Review 100(2): 1-10.

Einav L and Levin J (2014) Economics in the age of big data. Science 246(6210): n.p.

Papadimitriou CH (2001) Algorithms, games, and the Internet. STOC '01: 749-753, 752.

Tomasetti J (2016) Does Uber redefine the firm? The postindustrial corporation and advanced information technology. Hofstra Labor \& Employment Law Journal 34(1): 178. 